\title{
Process Arrangements for Variety, Retention, and Selection
}

\author{
Hans de Bruijn and Ernst F. ten Heuvelhof
}

This article argues that process management aimed at introducing variety, retention, and selection into complex decision-making processes can make a substantial contribution to improving them. It also describes process arrangements for variety, retention, and selection.

\section{Introduction}

\section{The Quality of Decision-Making}

When can we say that the quality of a decision or a change is either good or bad? What is good, what is bad, what is an improvement? These questions are important because so many decisions and changes have far-reaching consequences, cost a lot of money, have major positive and negative effects, among other things.

Questions about the quality of decisions and changes tend to be replaced by questions about the quality of the processes that bring about the decisions.' The reasoning will then be that a well-designed and well-managed decision-making

\footnotetext{
Hans de Bruijn is a professor in the School of Technology, Policy, and Management at Delft University of Technology. He received his Ph. D. in public administration at Erasmus University, Rotterdam. He is also program director at the Netherlands School of Public Administration and director of the TUD research program on multi actor systems. His research concerns networks and network-organizations, with a strong focus on governance and management issues in networks. He is the author on a number of internationally recognized books on these issues. His conceptual approach of these issues has been applied in research on the open source movement, frequency allocation, the design of policy instruments and mediation (e.g. interconnection disputes). He may be reached at $<$ j.a.debruijn@tbm.tudelft.nl>.

Ernst F. ten Heuvelhof (Chair of Public Management) is a professor in the Department of Public Management, School for Systems Engineering, Policy Analysis and Management of the Technical University of Delft, and at the Department of Public Administration of Erasmus University in Rotterdam. He is program leader of the Bsik research program Next Generation Infrastructures. He holds the post of chair research within the faculty. He may be reached at <e.f.tenheuvelhof@tbm.tudelft.nl>.
}

Knowledge, Technology, \& Policy, Winter 2004, Vol. 16, No. 4, pp. 91-108. 
process is certain to produce a good decision. ${ }^{2}$ In such processes, the decision will gradually evolve or improve, stimulated, as it were, by the arrangements operative in that process. An evolution takes place that will eventually result in the decision or the change. Such language makes it attractive to draw a parallel between decision-making and the quality of decisions on the one hand and evolution processes and the quality of species on the other. ${ }^{3}$ The mechanisms bringing about evolution in the theory of evolution could then be imitated in decision-making processes, allowing evolution to take place here, too, in decisions, that is to say a gradual improvement in the decisions made. These mechanisms are variety and selection.

\section{Tension between Variety and Selection}

It is not easy, however, to introduce variety and selection into decision-making processes in the proper doses. Many wish to see greater variety in the decisionmaking. They want more alternatives for solving the problem to be taken into account. They may even want the scope of the problem to become wider than the problem formulated by those who are in a hurry, believing they already know the solution. They also wish to retain the variety as long as possible (retention). Actors that already envisage the solution fail to see the use of such exercises. They urge a rapid, firm, and final selection, binding on those involved.

Too little variety in the process may prevent actors being able to identify with the problem or may cause alternatives that were not taken into account in the decision-making to keep hovering over the implementation arena. Too much variety can easily lead to "excessive expectations," slowness, inefficiency and, in the worst case, it may even cause the process to become bogged down.

Too quick a selection may prove to be the first step in a process suggestive of the "Echternach procession." Participants in this procession first take three steps forward and then two backward. In other words, a quick start may prove disappointing later. A hesitant selection, or too slow a selection, may cause unnecessary delay and chances being missed.

\section{Problem Definition in this Article}

This article explores possibilities for achieving optimum variety and selection in decision-making processes about change. What is optimum variety and selection in decision-making processes and with what process arrangements can we realize optimum variety and selection?

Variety and selection are emotionally charged concepts, because they are inextricably bound up with the evolution theory and therefore with ideas surrounding this theory. Although the use of such concepts may be fruitful because it brings new associations and ideas, it also poses risks. One of these might be the suggestion that introducing variety and selection in decision-making processes is bound to bring evolution, i.e. progress. Of course, it is not. What is true of the use of all metaphors is also true of the metaphor of variety and selection in decision-making processes: to a certain extent, the metaphor enriches, but at some stage the metaphor will lose its effect and may even become counterproductive. 


\section{Structure of the Article}

Section 2 will describe the complexity of the processes. This complexity is the environment relevant to the variety, retention, and selection. Section 3 presents brief definitions of variety, retention, and selection. The following sections present concrete arrangements for variety, retention, and selection. They will be followed by our conclusions.

\section{Complex Decision-Making: The Picture}

Variety, retention, and selection do not occur in a vacuum but in complex decision-making processes. In other words, these processes form the relevant selection environment for the resulting decisions. Complex decision-making processes have the following characteristics:

\section{Many Actors}

In complex processes, many actors operate. There may be sharp differences between them. Public actors and private ones, big ones and small ones, powerful ones and powerless ones, strictly organized actors along with diffusely structured actors, etc. Actors tend to be fragmented internally: an actor will then comprise sub-actors, which from time to time steer their own course. Actors do not all play the same role. Some of them are highly passionate about the issue; others operate in the background. Some are in the vanguard of the process; others form the rear guard. In many cases, the list of participants changes in the course of the process. New actors will join the process; others will abandon it. Some actors will move towards the center, others will gradually shift to the periphery.

\section{Divergent Views and Interests}

Actors hold divergent views in these processes. One may applaud what is anathema to another. All these actors try to get their way in the process, which is why they participate. Actors' behavior will be both reflexive and strategic. They reflect about what they are doing, what their opening move will be and when and with what force they will intervene. Actors take these positions to promote underlying interests, feeling that adopting a concrete stance will serve their interests. Up to a point, their positions and interests are variable.

\section{Actors Are Both Interdependent and Each Other's Competitors ${ }^{4}$}

Actors frequently find that they need each other to achieve something. They are interdependent. The dependencies exist in many dimensions: financial, legal, information, land, communication, etc. Dealing with these dependencies properly demands empathy with each other. But there are also business relations between them. For example, they are each other's suppliers or customers, or their relation may be that of a norm addressee and a licensing authority. Occasionally, they may even be 
Table 1. Four Types of Policy Problems

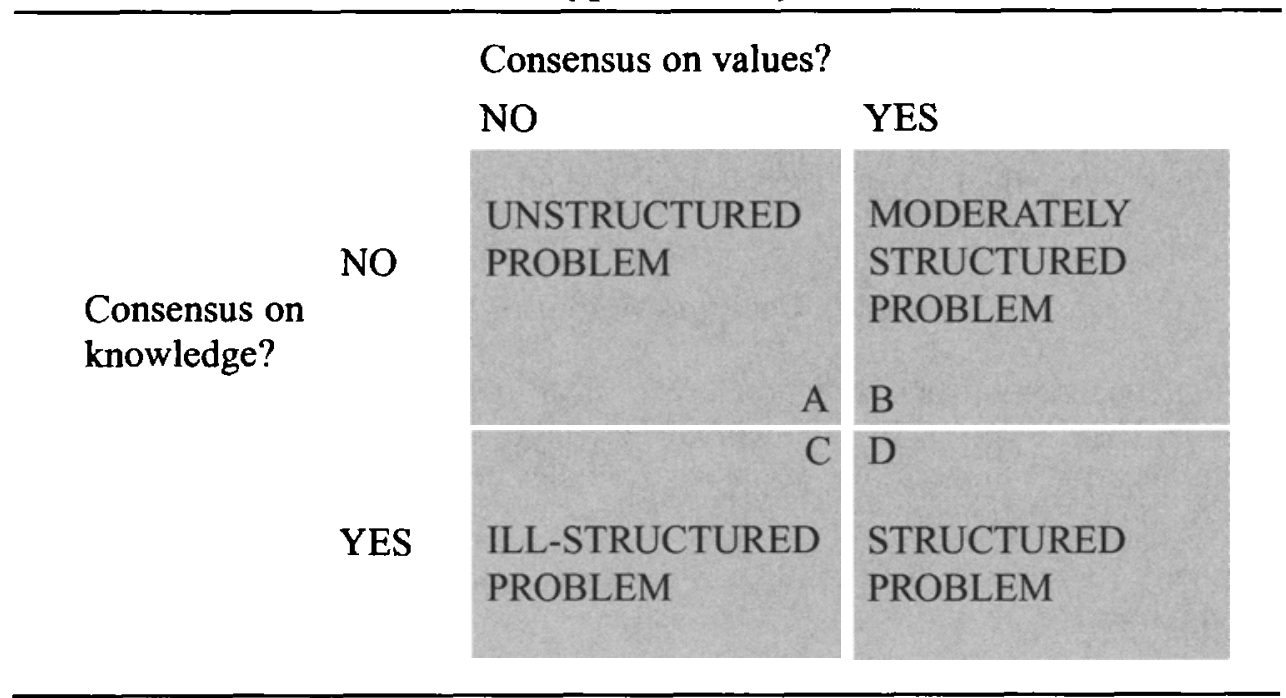

each other's competitors. Such relations demand a certain distance and pragmatism. Empathy on the one hand and pragmatism and distance on the other are not always easy to combine in relations between actors.

\section{Unstructured Problems}

The problems in such processes are unstructured. Table 1 characterizes unstructured or contested problems. ${ }^{5}$ Such problems exist when facts cannot be established objectively because the data, system boundaries and methods used are open to discussion.

Many data are unavailable and still have to be generated. Fully reliable data collection is almost impossible. The system boundaries cannot be established objectively. For example, when the environmental impact of the transport of raw materials for packages has to be defined, should the environmental impact of producing the means of transport be included? Discussion is possible about the methods used.

\section{Divergent Perceptions and Meaning-Giving}

The participating actors have different perceptions of each other. Each takes their own view of "the problem." Each has their own idea about the causes of the problem and about the possibilities of solving it. The divergent interests in combination with the different perceptions cause actors to attach different meanings to events in the process.

\section{Temporary Capriciousness}

Temporarily, there is little structure in decision-making processes. Although some authors speak of "phases" in processes, ${ }^{6}$ there is hardly any empirical evidence of 
these phases. The activities required for decision-making succeed each other in a surprising manner or even take place simultaneously. Sometimes, developments in the processes take place very quickly. At other times, progress is extremely slow. Many processes lack a clear beginning and a clear end. ${ }^{\text {? }}$

\section{Substantive Capriciousness Because of Couplings}

Interdependent actors wanting each other's support may easily end up in a deadlock. A process is deadlocked when it does not make any progress, for example because an actor refuses to cooperate. This actor may already have contributed a great deal to the progress. However, if it receives nothing in return-just because in this process it needs nothing from the other actors-at some stage it will no longer be prepared to contribute. The process can then only be taken forward by coupling it to another process in which this one actor needs the help of other actors. This creates new possibilities for exchanges. Couplings between issues and processes can therefore contribute to the progress. These couplings may be opportune from a management point of view, but surprising, if not capricious, from a substantive view.

\section{Emergent Results}

Because so many actors participate and each of them does so out of its own particular interest, a mix of ideas, ambitions, interventions, and blockades evolves, resulting in "decisions" that are emergent rather than designed or devised. They result from the efforts and forces of actors that-each in their own way-try to influence the course of the process. No one ever conceived this result.

\section{A Decision-Making Process Is a Negotiation Process}

Because of all these factors together, decision-making is a negotiation process. The parties' interdependence brings them together. They have to cooperate. However, they will not automatically agree, because they are dealing with unstructured problems, about which they disagree by definition. Actors may be prepared to commit themselves to negotiation processes and their results by coupling the problem to other problems, which gives rise to the substantive capriciousness with its emergent results. Only concord between a majority of the most powerful parties will produce agreements that will work. In other words, only negotiated results will carry over into the implementation.

\section{Variety, Selection, and Retention}

What can augment the satisfaction of actors with such processes and their outcome? What can speed up and facilitate these processes? How can we introduce quality into such capricious processes? Although quality is an ambiguous concept in this context, we can make a number of general remarks about it. To create quality in such processes three conditions always have to be met. The first is variety in the process. The second is selection. Coupling variety and selection requires a third characteristic of change processes: retention. We will briefly discuss variety, selec- 
tion, and retention in this section. Variety, selection, and retention are introduced into change processes by means of process management. After briefly introducing process management in section 5 , we will discuss variety, selection, and retention in more detail in the following sections.

\section{Variety}

Variety is manifested in open processes. Open to actors, to problems and to solutions. Only if the variety is safeguarded and the process is open in this sense will actors identify themselves with the process. Only if a wide range of solutions has actually been discussed in the process will actors impart that they have not overlooked any serious solutions. In short, variety is needed not only for the quality of the outcome of the process, but also for the legitimacy of the decision-making.

\section{Selection}

In the process, a selection has to be made from the variety available. This selection is needed for eventual implementation. For the process as a whole to be legitimate, the selection needs to be made in an authoritative manner. First, it is important here that the selection should be coupled to the variety, i.e. that the entire variety is eligible for selection. Second, the selection process itself should be arranged and managed as a sub-process.

\section{Retention}

Retention is the bridge between variety and selection. Retention is the ability to store and process variety. Proper retention aims to retain maximum variety in the process as long as possible without unnecessarily hampering the process. Retention takes the edges off the selection process. Retention contributes to maintaining variety in the process as long as possible. This increases the adaptive power of the process, i.e. the process can continue to move with the relevant dynamic in its environment for a longer period.

\section{Process Management}

Decision-making about change can be managed more or less deliberately as a process. If there is no deliberate steering on quality of the process, the decisionmaking will be relatively spontaneous, containing some, but probably not optimum, variety and selection. Process management is an alternative to such spontaneous development. The point of departure for process management is that substantive analysis offers no solution for unstructured problems that commands wide support and is therefore feasible. This is why process management focuses on the process that has to bring a solution. In the process, rules develop, with the help of which actors eventually reach a substantive solution. Process arrangements develop in the interactions between the actors involved, although a process manager may deliberately design and introduce them. Process managers may have various 
backgrounds. For example, a process manager may be an actor feeling a great sense of urgency or an independent third party that was specially commissioned.

Process management is realized by the development of "process arrangements." These arrangements influence both the process and its quality. Process management explores the possibilities of introducing optimum variety, retention, and selection in change processes with the help of process arrangements.

Process arrangements affect the behavior of actors in change processes. It is these actors that give concrete shape to the variety, selection, and retention and support it. Two types of actors play a leading part in such processes: the actors concerned and scientific experts.

\section{Actors Concerned}

A distinction into three groups of actors is relevant in managing decision-making processes: ${ }^{8}$

- Parties that have blocking power in decision-making

These parties can block the decision-making. Involving them in a process may prevent them from exercising their blocking power, thus frustrating the decision-making. The question here is, of course, whether this mechanism will actually operate. When a process has insufficient appeal for parties, they will exercise their blocking power during this process; this consideration may be a reason not to invite the party concerned. A decision like the latter will, of course, depend on how much blocking power a party has. If it is absolute, there is no sense in excluding it.

- Parties that have productive power in decision-making

These parties have the means to actually realize a decision or participate in realizing it. Examples of such means are money, powers, relations, or physical resources.

- Parties that have an interest in the decision-making without being able to contribute to the solution of a problem or to block a solution

An example would be a process dealing with the expansion of an airport. There may be certain municipalities, situated at a considerable distance from the airport, because of which they have hardly any formal or legal resources to influence the decision-making. If these municipalities nevertheless suffer a noise nuisance, the airport manager might involve these municipalities in the decision-making on moral grounds.

The latter example shows that there are more reasons than merely those of power. There may be important moral grounds for involving particular parties in the decision-making. In almost every process, there are parties whose power is negligible, but which may be affected by a potential decision.

\section{Scientific Experts}

A second driver for variety in processes comes from the world of knowledge and science. Experts have their own perspectives on the problem and the solutions. 
They will try to explain the problem and their solutions match what they see as the causes of the problem. Their input should prevent disproportionate political rationality: "speaking truth to power" is their motto. They should be able to impose limits on the political rationality dominant among the actors concerned. The input of scientific expertise is not uncontested, however. Weingart introduces two paradoxes in the relation between scientific expertise and decision-making that problematize this relation. ${ }^{10}$ The first paradox has to do with the simultaneous scientification of politics and the politicization of science. Policy increasingly has to be rationalized by expertise. Expertise particularly lends itself to this purpose because it is independent of policy. But the reality is different. Policy and expertise need each other and are therefore intertwined. This gives rise to the paradox: policy increases its use of scientific expertise to boost its justification. However, the more intensive this use becomes, the more the independence between the two decreases. Nevertheless, the relation was relevant because of this independence. The paradox becomes explicit in the eroding authority of scientific expertise, i.e. scientific expertise in change processes is received more and more cynically, and it is attacked.

The second paradox is that, despite this paradox, decision-makers continue to rely on scientific expertise and that the experts do not draw the obvious conclusions from it about their relation with decision-makers.

We can solve these paradoxes by explicitly distinguishing between the phases in which the focus is on variety and the phases in which the focus is on selection. The format of scientific expertise in the context of generating variety differs from the format of scientific expertise for selection purposes.

\section{Variety}

\section{Commitment by Means of Confidence in the Process}

Process arrangements should aim to inspire confidence in the process in the relevant actors. It is important here that each actor should recognize its own problems and solutions in the process. They should therefore be admitted to the process with their problems and solutions, but-and this is the other side of the medal-they should also be prepared to join the process. Process arrangements should consider these two requirements and keep the balance between them.

Confidence by establishing the problem and the solution space by means of a process variety involves the scope of the problem agenda and the scope of the solution space.

\section{Negotiated Scope of the Problem}

In general, one of the initiators has a particular problem that it feels is urgent. It realizes that it needs other actors to solve it. It may already have that solution in mind. The question is, however, whether these actors will be prepared to accept the initiator's problem definition. They are more likely to want to start a discussion about the problem. They will want to modify its formulation, widen the problem, or narrow it down. All this against the background of the problems they regard as 
relevant. The problem will therefore not be the real problem until the parties agree about it. Consequently, the scope of the problem is a negotiated scope. In other words, the problem is the output of a sub-process rather than the input for the decision-making process. Even at a later stage, the parties will try to influence the nature and the scope of the problem, which again requires space.

\section{Negotiated Scope of the Solutions}

What is true of the delineation of the problem is also true of the search space for solutions. Here, too, the parties need to agree about what options will be examined for their solution power. The legitimacy of the process will be compromised if a solution regarded by one of the parties as promising is not given a significant place in the process. Such an option will then continue to "hover" over the process as a promise never seriously examined. The parties will stick to their view that the chosen solution is not the best, which of course inhibits their loyal cooperation in the implementation.

\section{Process Arrangements to Generate Variety}

- Protection for a broad scope of problems and solutions

An explicit rule of the game might be that problems and solutions submitted by actors that participate in the process will be judged for their relevance and their merits. More specifically, if the primary policy problem is traffic congestion and environmentalists are invited to participate in contemplating solutions, the process should be open to the problems they submit (e.g. sustainability) and to the directions towards a solution they have in mind (e.g. promoting public transport, building sunken roads, etc.)

- Space for diversity of roles

Not all actors that participate need to play the same roles in the process and participate with the same intensity. The variety in intensity can be introduced in various ways. A steering-group-and-work-groups arrangement can be used. Some actors participate in the steering group; others confine themselves to participating in work groups. Another arrangement is that some actors participate in the discussions about all subjects, while others only participate in the discussion of matters that concern them. Another variant, in conclusion, is a distinction between actors that actively participate in decision-making and actors that only want to be consulted.

- Space for creativity and competition Creativity-promoting techniques can help to increase variety. One example is brainstorming techniques. Space should be created for such techniques in processes and sub-processes. Another way of bringing creativity into the process is introducing competition. For a certain time, the parties work independently of each other, with a reward promised for the party with the most fruitful results. This is a form of creative competition."

- Position expertise, notably "freischwebende Intelligenz" in the process Scientists are able to couple problems and solutions in a way that surprises the actors concerned. They have other experiences and a network of connections other than 
that of the actors, and will be able to make surprising couplings that can take the discussion forward.

\section{Process Arrangements to Manage the Variety}

All these arrangements call for openness, allowing great variety in the process. This may cause concern about the manageability of the process: will it not become chaotic? Will a process shaped in such a way not create expectations that can never be realized? The paradox is that while openness may appear to bring lack of control, in reality it creates trust, which is a good basis for decision-making. ${ }^{12}$

However, this does not alter the fact that too much variety can frustrate a process. For actors, the process may all too easily pose a threat because it may take any course. Moreover, the process may become very time-consuming. That is why it is necessary to manage the variety, for which the following arrangements might be suggested.

- Commitment to the process rather than to the result

In many cases, the variety of roles correlates with the commitment of actors to the process. The weightier the role is, the stronger their commitment will be. Of course, the price paid for an important role and a strong influence on the process is a close commitment to it. In other words, actors that played a key role in the process have little space to distance themselves from the result of the process, let alone from the process itself. The lighter the role in and the commitment to the process is the more space actors have to distance themselves from the process.

However, the large variety introduced into the process makes ex ante commitment difficult. This poses a dilemma for actors that play a major role in the process and are prepared to admit variety to the process. In the eyes of such an actor, the process may take any course, which makes ex ante commitment extremely risky, but the actor's key role stands in the way of non-commitment.

It is precisely this dilemma that keeps many actors from participating heavily in a process. They feel that, by participating, they walk into a trap from which there is no way back. Process arrangements should be aimed at mitigating this dilemma. Parties cannot be asked to commit themselves ex ante to the result of the process, even though it was achieved honestly and fairly; all that can be asked is commitment to the process. This lessens the actor's misgiving that it is about to walk into a trap and raises the chance that it will perceive the process as a safe and interesting environment. Whether parties commit themselves to the final result will depend on the quality of the process and on the result. Of course, this is the right incentive to manage the process properly.

- Coupling ideas to expertise

Generating variety may easily become "too successful." Although, in that case, great variety is created, the quality of some of it is dubious from any perspective. The problem definition has been stretched in a direction that, prima facie, is nonsensical, or solution directions have been introduced that are visibly unrealistic and infeasible. The input of experts may prevent this. Of course, what experts are needed here depends on the problem and the nature of the solutions put forward. In many cases, technical, legal, and financial expertise will be required. 
- Introduce incentives that encourage actors to suggest alternative options for research early in the process ${ }^{13}$

Actors plan the moment for suggesting alternative options to the process strategically. Suggesting these options early on may give the option a lasting influence on the agenda, but the risk that such a strategy will halt the process is significant. Keeping options in reserve may also be strategic. In some cases, playing a trump card at a later stage may permanently settle the debate. There is a risk that there will be no space left for the option. The process as a whole will gain from a maximum variety of options as early as possible. The options can then be examined simultaneously and the selection can be based on this variety. The incentive for putting forward suggestions early on might be help in developing the option or a guarantee for serious contemplation of the alternative.

\section{Retention}

The more of their problems and solutions actors recognize in the process, the greater their commitment to the process will be. They will feel that the process matters to them and that developments are taking place there that serve their interests. This is an argument not only for introducing maximum variety into the process, but also for retaining the variety in the process as long as possible, in other words for keeping the selection modest and postponing it as long as possible. However, this will come at a price. After all, it takes considerable effort to manage a process that contains great variety, which remains in the process for a long time. Formulated like this, a dilemma presents itself here: although great variety in the process inspires confidence in actors, who will therefore be committed to the process, the same variety makes the process complex and difficult to manage, and time-consuming. It may even cause the process to become deadlocked. A properly functioning retention mechanism may offer an escape from this dilemma. ${ }^{14}$ It may allow variety and selection to be united to a certain degree and may keep the process manageable, without the variety becoming too limited.

\section{Process Arrangements for Retention ${ }^{15}$}

The following arrangements contribute to retention:

- Synthesis will absorb variety; the chance of synthesis increases by negotiating on the level of interests.

A familiar example: two parties both claim a consignment of oranges. The conflict appears to be insoluble because both claim exactly the same and what one of them receives will reduce the part the other will acquire. At one stage, the discussion shifts from the parties' views to their interests. The interest of the one party appears to be the continuity of its soft drinks plant. It needs the oranges for the orange juice. The other party has an entirely different interest. It makes perfumes and needs the orange peels to manufacture them. Now that the two parties know each other's interests, they are able to solve the conflict completely in a most elegant way. In this case, the solution is obvious. The one party receives the flesh of all the oranges, the other party gets all the peels. Both are fully satisfied, because the interests of both have been fully served. Had the discussion not been conducted on the level of the interests, the parties might have reached a compromise of 50 percent of the oranges for 
the one and 50 percent for the other. Negotiating on the level of interests has brought the parties a far better result. Variety was maintained, but a strict selection was made as well. The process is easy to manage and can produce a quick solution.

- Developing options side by side

The parties agree to examine whether it is possible to implement the two proposals in parallel and in tandem. The parties examine until what time this is possible and what conditions should be met to develop the two proposals in parallel. They agree a monitoring process that produces data to discuss the dilemma again at a later stage, based on more data than are available now, and jointly gathered data.

\section{- Pilot project option}

The parties decide to implement one of the options fully and to introduce the other option on a modest scale as a pilot scheme. Actors arrange a process in which they jointly monitor the results of the pilot scheme. If the results of the pilot scheme are positive, the parties will reconsider their earlier decision.

\section{- Mothball variant}

The parties choose one of the options and decide to keep the other available, too, as much as possible. This means that resources are freed up to maintain the knowledge about this option; that, if relevant - from a spatial perspective-this option is not precluded for good and all, etc. If desired, the variant rejected in the decision-making can be taken out of mothballs at once.

\section{- Growth model}

The parties examine whether it will be possible in the course of time for the one option to develop further into the other option.

- Removing the sting from the conflict; tackling the underlying question

The parties in the process examine whether there are any factors behind the dilemma that cause the conflict to continue. If they trace them, they start a research or advice process that should lead to broadly supported conclusions about the validity and the relevance of these factors. In a discussion about whether return packaging or disposable packaging is better for the environment, such an underlying variable was found to dominate the discussion. The underlying factor proved to be the number of times a return package is used ("number of trips"). Most of the parties that differed so sharply about whether disposable packaging or return packaging was better for the environment were found to support the following theorem: "If there are many trips, the return bottle wins. If there are few trips, the disposable package is better." The sting in the conflict proved to be the number of trips packaging made. Some parties believed that the average return package made many trips before becoming worthless, other parties did not believe this and argued that return packaging made few trips.

The process architect that discovers such an underlying factor can design a research protocol to solve the dilemma. The outcome that surprised all parties was that this sensitivity is very limited. The number of trips proved to be far less decisive for the difference in environmental impact than actors believed it to be at the start of the process. This removed the sting from the conflict.

- Mitigating and/or compensating measures

If the effects of particular options are inevitable after selection and the parties largely 
agree about the adverse consequences of these options for other parties, the process architect can outline a process that leads to measures that mitigate or compensate the adverse effects. This takes the edge off the selection.

\section{Selection}

In the selection, the participants in the process reduce the variety: they focus the problem and diminish the range of solution directions. This reduction continues until the parties are able to take action. Implementation has then begun.

The following conditions must be met for an authoritative selection:

\section{The Selection Should Cover the Whole Variety}

Empirical research shows that the entire wealth of ideas generated in sub-processes based on generating variety does not always return in the selection phases. ${ }^{16}$ In that case, variety and selection are sub-processes run relatively independently of each other, which may lead to loss of quality and inevitably leads to frustration about the course of events. A necessary condition for a qualitatively good selection process is that the selection should cover the whole of the variety. ${ }^{17}$

\section{Negotiated Selection}

Like variety, selection takes place by means of negotiation. Only negotiated selection is authoritative selection, subject to the requirements for the arrangement of these negotiation processes. Only through negotiations can the parties reach agreement about what selection is desired.

On the basis of such conditions, Edelenbos arrives at the norm of absorption gradation. ${ }^{18}$ He distinguishes three degrees:

- Complete absorption (selection as a "sponge"): the variety fully carries over into the selection.

- Partial absorption (selection as a "sieve"): the ideas from the variety are transformed, discolored, or partly taken over.

- No absorption at all, or no recognizable absorption (selection as a "shield"): the ideas from the variety are either taken over in an unrecognizable form or not taken over at all.

\section{Process Arrangements for Selection}

The following arrangements contribute to an efficient selection:

- Proper interconnection between scientific expertise and management ${ }^{19}$

Scientific expertise may help to cut Gordian knots if actors are unable to untie them at management level. The reverse is possible, too. Managers then contribute to solving scientific controversies by deciding the issue on the management level. In both 
cases, a stranded selection process is refloated by transferring the issue from the scientific arena to the management arena and vice versa.

- Loose coupling between selection and continuation

Selection as negotiation is easier if the negotiating parties are offered space to reverse their concessions or their acceptance of the selection. The parties should be offered the space to distance themselves from earlier selection results later in the process. Process rules can specify the conditions under which this is allowed. Process management should seek to ensure that the quality of the process and its result are such that it is an interesting option for none of the parties to actually use this option.

\section{- Coupling to other processes}

Selection processes can be easier if several selection processes, in which a number of the same actors play a role, are coupled and run in parallel. The exchange processes can then cover several processes, which offers more possibilities to achieve results that satisfy all parties. However, decoupling may also be useful, for example if problems in one process unnecessarily delay progress in another process.

\section{- Avoid "mandated science"20}

"Mandated science" exists if the actors mandate scientists to make a decision. In the whole of their decisions, the actors distinguish a number of sub-decisions that they leave to scientists. The advantage of this arrangement seems to be that a decision about which the actors cannot agree is left to others, viz. scientists. This is expected to have a de-politicizing effect. In reality, however, the actors will continue their game, also in the scientific world, and in this game the scientists seek to present an outcome that pleases them as the uncontested result of scientific research. This will politicize the research rather than depoliticize the decision-making.

- Facilitate "negotiated knowledge"22

The only knowledge that will actually play a role in such processes is "negotiated knowledge." This is knowledge that meets two conditions. The first is that the actors accept it and the second is that it will stand the test of scientificity. It is important for the acceptance of the findings of scientific research by the parties concerned that they can participate in the negotiations about the design of the research, the problem definition of the research and the presentation of its findings. In many cases, this will be indirect participation, in the form of scientists that at least have some affinity with the actors. This creates a "second negotiating table" where negotiation takes place in more scientific terminology and scientists try to find arrangements to which all parties can commit themselves. This phenomenon entails the risk of "negotiated nonsense." Although the parties reach agreement, they agree nonsense. This risk is reduced by systematically submitting the outcome to experts, for example in the form of a "peer review."

\section{- Transparent and external judgment}

To be authoritative, the selection process should be transparent to at least the actors involved. Submitting the selection process to external parties (e.g. authoritative managers and scientists) afterwards and asking them to judge the selection for quality promotes the transparency. Making this agreement before the selection and laying down that the result of the audit will be public is an incentive for careful selection. 
Table 2

Process Arrangements for Variety, Retention, and Selection

\begin{tabular}{|c|c|c|}
\hline $\begin{array}{l}\text { The arrangements } \\
\text { concern: }\end{array}$ & Actors concerned & Scientific experts \\
\hline \multicolumn{3}{|l|}{$\begin{array}{l}\text { Arrangements } \\
\text { aimed at realizing: }\end{array}$} \\
\hline & $\begin{array}{l}\text { Protection of a broad scope } \\
\text { of problems and behavior } \\
\text { - Space for a multiplicity of } \\
\text { roles } \\
\text { - Space for creativity and } \\
\text { competition } \\
\text { - Incentive to introduce } \\
\text { variety early on }\end{array}$ & $\begin{array}{l}\text { Space for expertise, } \\
\text { notably } \\
\text { 'Freischwebende } \\
\text { Intelligenz' } \\
\text { - Coupling ideas of actors } \\
\text { concerned and scientific } \\
\text { expertise }\end{array}$ \\
\hline Retention & $\begin{array}{l}\text { - Synthesis } \\
\text { - Options in parallel } \\
\text { - Pilot scheme options } \\
\text { - Mothball variant } \\
\text { - Growth model } \\
\text { - Mitigating and/or } \\
\text { compensating measures }\end{array}$ & $\begin{array}{l}\text { - Removing the sting from } \\
\text { the conflict; tackling the } \\
\text { underlying question }\end{array}$ \\
\hline Selection & $\begin{array}{l}\text { - Loose coupling between } \\
\text { selection and continuation } \\
\text { - Coupling to other processes } \\
\text { - Avoiding "mandated } \\
\text { science" } \\
\text { - Facilitating "negotiated } \\
\text { knowledge" } \\
\text { - Transparent and external } \\
\text { judgment }\end{array}$ & $\begin{array}{l}\text { Interconnection between } \\
\text { scientific expertise and } \\
\text { negotiations between } \\
\text { actors concerned }\end{array}$ \\
\hline
\end{tabular}

\section{Summary and Conclusions}

Table 2 is a schematic representation of the process arrangements set out in the preceding sections.

Variety, retention, and selection are introduced in change processes with the help of these process arrangements. They affect either the actors or the scientific experts. The following conclusions go together with this overview of process arrangements:

Changing Is Negotiating; Negotiating About Process Arrangements, About Variety, Retention, and Selection and About the Outcome.

Essentially, processes are negotiating processes between actors. The relevant actors arrive at such arrangements in negotiating processes. These actors also give real meaning to such a rule in the negotiation processes. With the help of such 
arrangements, actors achieve the desired variety, retention, and selection, and eventually make decisions, also in negotiation processes.

Although Variety, Selection, and Retention Are Not Arranged in Series, They Do Provide Some Structure.

At the beginning of this article, we concluded that complex processes are not as neatly phased as some might wish. Such processes repeatedly prove to be temporarily capricious. The arrangements of variety, selection, and capriciousness do not alter this. Even with these arrangements, the processes continue to develop capriciously for the short term. Nevertheless, variety dominates in some phases and retention and selection dominate in other processes, but the separation between them and the order in time are not absolute.

\section{Interaction between Actors and Scientific Experts Required.}

Two categories of actors are essential in such processes: the category of the actors and that of the scientific experts. The adage that research and decision-making should be strictly separated is unfruitful in such processes. However, the two should not be fully merged either. Scientific expertise and the conflict of interests should be intertwined, provided it is done properly.

\section{Interaction by Means of Intertwining Has Two Functions.}

Some interaction between experts and actors has at least two functions. The first stems from the unstructured nature of the decision-making. The problem definition and solutions will keep changing because of this unstructured nature. Experts can contain this dynamic within certain limits by indicating what is impossible or indefensible from a scientific point of view. Occasionally, experts can have a depoliticizing effect. In some cases, sensitivity analyses can show that some differences of opinion between actors have no bearing on the results. The conflict has then become pointless, which results in some depoliticizing. A second function is that, because actors' interests are at stake, they will be encouraged to ask the experts critical questions and thus find out what is hard and uncontested and what is softer and more subjective.

\section{Do Not Couple Tightly.}

However, the coupling should not be permanent and total. Experts should also be able to carry out research independently of the actors. Only thus can Weingart's two paradoxes mentioned above be solved. This preserves the status of the community of scientific experts and continues to make them an interesting partner in such processes for that very reason.

\section{Do Not Limit Scientific Expertise to One Phase.}

The notion that research can remain limited to one phase in the process also ignores the capricious course of such processes and will therefore not stand up. 
Because of their capricious nature, it is uncertain whether the research will be given sufficient time. If, during the research phase, actors discover opportunities to perform actions that may benefit them, they will not fail to perform them. The reverse is true as well: researchers will continue to interfere in the process both before and after that phase, irrespective of the time when they are brought in formally. In short, we can expect little actual ordering of a research phase of their own.

\section{Organize Knowledge Development and Decision-Making in Parallel, with Periodic and Loose Couplings Organized Ad Hoc.}

The alternative is that the research is also organized as a process covering a longer period. Parallel coupling between research and a primary decision-making process enable the two functions of interconnection between research and decision-making described above to be carried out during the whole of process rather than during a short period. However, the interconnection must not be a total one, but should be periodical, frequent and, if necessary, ad hoc. The result should be a loose coupling between the two.

\section{Variety, Retention, and Selection Satisfy Actors.}

Managing complex processes will always be problematic. It will always be difficult to satisfy all actors with the process and its results. Absolute satisfaction is almost impossible if we remember that it may be strategically imprudent for actors to admit that they are satisfied, because this might weaken their position in future negotiating processes. It would therefore be unwise to overestimate the importance of the explicit satisfaction or dissatisfaction with these processes.

\section{Variety, Retention, and Selection Bring Quality in Decision-Making Processes and Quality of Decisions.}

Introducing the arrangements mentioned in Table 2 will bring optimum variety, retention, and selection. Consequently, they will contribute to greater satisfaction among the actors involved in the decision-making. As a result of the relationship between the quality of the process and the quality of the decisions resulting from the process in the beginning of this article, introducing these arrangements will also improve the quality of the decision.

\section{Notes}

1. Bruijn, Hans de, Ernst ten Heuvelhof, and Roel in 't Veld. (2002), Process Management, Why Project Management Fails in Complex Decision-Making Processes, Boston: Kluwer Academic Publishers.

2. Simon, H. A. "From substantive to procedural rationality," in Simon, H. A. Models of Bounded Rationality, Vol. 2: Behavioral Economics and Business Organization, Cambridge, MA: The MIT Press.

3. e.g. De Jong, M. (1999), Institutional Transplantation. How to Adopt Good Transport Infrastructure Decision-Making Ideas from Other Countries, Delft.

4. Chisholm, D. (1989), Coordination without Hierarchy, Berkeley CA: University of California Press. Marin, B. and R. Mayntz. (1991), Policy Networks, Empirical Evidence, and Theoretical 
Considerations, Frankfurt am Main. Bohman, J. (1996), Public Deliberation: Pluralism, Complexity, and Democracy, Cambridge, MA: MIT Press.

5. Hisschemoller, M., Democratie van problemen. De relatie tussen de inhoud van beleidsproblemen en methoden van politieke besluitvorming. Amsterdam VU publishers, 1993 [Democracy of Problems. The Relation between the Substance of Policy Problems and Methods of Political Decision-Making].

6. Miser, H. J. and E. S. Quade. (1985), Handbook of Systems Analysis, Part I. Overview of Uses, Procedures, Application, and Practice, North Holland, Amsterdam.

7. Braybrooke, D. (1974), Traffic Congestion Goes Through the Issue-Machine, London and Boston: Routledge \& Kegan Paul. Cohen, M. D. et al. (1972), "A garbage can model of organizational choice," in Administrative Science Quarterly, 17 (1), 1-25. Mintzberg, H. (1976), "The structure of "unstructured' decision processes," in Administrative Science Quarterly, Vol. 21, 246-275. Teisman, G. R. (2000) "Models for research into decision-making processes: on phases, streams, and decision-making rounds in Public Administration, 78 (4), 937-956.

8. Bosch, van den F.A.J and S. Postma. (1995), Strategic Stakeholder Management: A Description of the Decision-Making Process of a Mega-Investment Project at Europe's Biggest Oil Refinery: Shell Nederland Raffinaderij BV in Rotterdam, Erasmus University/Rotterdam School of Management, Management Reports Series No. 242, Rotterdam, 328. Galbraith J. R, (1995), Designing Organizations: An Executive Briefing on Strategy, Structure and Process. San Francisco, CA: Jossey Bass.

9. Wildavsky, A. (1979), Speaking Truth to Power: The Art and Craft of Policy Analysis, Boston.

10. Weingart, P. (1999), "Scientific expertise and political accountability: paradoxes of science in politics." In Science and Public Policy, Vol. 26 (3), 151-163.

11. Teisman, G. R. (1997) Sturen via creatieve concurrentie, KUN, Nijmegen, [Managing Through Creative Competition.]

12. de Bruijn, J. A., E. F. ten Heuvelhof, "Process Management," In van Heffen et al., Governance in Modern Society, 313-328, p. 324.

13. van Eeten, M. and E. ten Heuvelhof. (1998), "Serviceable truth": de procescontingente inzet van wetenschappelijke expertise in Bouwstenen voor argumentatieve beleidsanalyse, Rob Hoppe en Aat Peters (red), Elsevier, Den Haag. [The process-contingent use of scientific expertise in Building Blocks for Argumentative Policy Analysis.]

14. Campbell, D. T. (1987), "Evolutionary epistemology," in Radnitzky, G., W.W. Barttley (eds.), Evolutionary Epistemology, Rationality and the Sociology of Knowledge, La Salle, Illinois: Open Court

15. Bruijn, Hans de, Ernst ten Heuvelhof and Roel in 't Veld. (2002), Process Management, Why Project Management Fails in Complex Decision-Making Processes, Dordrecht: Kluwer Academic Publishers.

16. Teisman, G. R. (1997), Sturen via creatieve concurrentie, Nijmegen, [Managing through Creative Competition.]

17. de Jong, M. (1999), Institutional Transplantation. How to Adopt Good Transport Infrastructure Decision-Making Ideas from Other Countries, Delft, 69.

18. Edelenbos, J. (2000), Proces in Vorm, Utrecht, 183 [Process in Form, 2000].

19. van Eeten, M. and E. ten Heuvelhof. (1998), 'Serviceable truth': de procescontingente inzet van wetenschappelijke expertise in Bouwstenen voor argumentatieve beleidsanalyse, Rob Hoppe en Aat Peters (red), Elsevier, Den Haag, [The process-contingent use of scientific expertise.]

20. van Eeten, M. and E. ten Heuvelhof. (1998), "Serviceable truth": de procescontingente inzet van wetenschappelijke expertise in Bouwstenen voor argumentatieve beleidsanalyse, Rob Hoppe en Aat Peters (red), Elsevier, Den Haag [The process-contingent use of scientific expertise.]

21. Salter, L. (1988), Mandated Science, Science and Scientists in the Making of Standards, Boston: Kluwer Academic Press.

22. van Eeten, M. and E. ten Heuvelhof. (1998), "Serviceable truth": de procescontingente inzet van wetenschappelijke expertise in Bouwstenen voor argumentatieve beleidsanalyse, Rob Hoppe en Aat Peters (red), Elsevier, Den Haag, 1998 [The process-contingent use of scientific expertise]. 